\title{
Acute Ophthalmic Manifestations in Mycoplasma Induced Rash and Mucositis
}

\author{
Ramy Rashad \\ Massachusetts Eye and Ear Infirmary \\ Abdelrahman M. Elhusseiny \\ Boston Children's Hospital \\ Swapna S. Shanbhag \\ Massachusetts Eye and Ear Infirmary \\ James Chodosh \\ Massachusetts Eye and Ear Infirmary \\ Hajirah N. Saeed ( $\sim$ Hajirah_Saeed@meei.harvard.edu ) \\ Massachusetts Eye and Ear Infirmary
}

\section{Research Article}

Keywords: Mycoplasma induced rash and mucositis, pneumonia, conjunctival hyperemia, meibomitis, trichiasis, Stevens Johnson syndrome

Posted Date: July 14th, 2021

DOl: https://doi.org/10.21203/rs.3.rs-635668/v1

License: @ (i) This work is licensed under a Creative Commons Attribution 4.0 International License. Read Full License

Version of Record: A version of this preprint was published at The Ocular Surface on March 1st, 2022. See the published version at https://doi.org/10.1016/j.jtos.2022.03.004. 


\section{Abstract}

Background: The purpose of the current study is to demonstrate the prevalence of ocular complications in patients suffering with MIRM, an eruption clinically distinct from Stevens-Johnson syndrome/toxic epidermal necrolysis (SJS/TEN).

Methods: In this retrospective observational study, we identified all patients in our hospital database who were diagnosed with MIRM. Diagnosis was confirmed by clinical information and a positive Mycoplasma pneumoniae serology. Only patients with available records with formal ophthalmology consults were included. Clinical and laboratory data were collected from our electronic medical record system.

Results: A total of 11 patients were included in our study. The average age was $22 \pm 15.2$ years, and the majority were male (63.6\%). In all 22 eyes, the acute ocular findings were limited to conjunctival hyperemia $(n=18,81.8 \%)$, meibomitis $(n=2,9.1 \%)$, and conjunctival epithelial defects $(n=1,4.5 \%)$. None of the patients were treated with amniotic membrane transplantation in the acute phase. Three patients received follow-up eye examinations; none showed ocular complications.

Conclusions: Ocular complications from MIRM appear to be milder in comparison to ocular complications found in other bullous and inflammatory conditions such as SJS/TEN. Understanding the ocular sequelae of MIRM is important to better inform acute and chronic management.

\section{Background}

Mycoplasma pneumoniae is an atypical bacterium characterized by the absence of a cell wall and an ability to ubiquitously mimic host cell surface composition, making it highly resistant to antibiotics. It was first isolated in 1898 by Nocrad and Roux from bovine tissue but not isolated in humans until 1944.(1) It is most commonly known for causing atypical pneumonia and upper respiratory tract illness. Through the years, it has also been recognized as a culprit in extra-pulmonary complications, most commonly neurologic and/or cutaneous. $(2,3)$ Historically, its cutaneous involvement was categorized as an erythema multiforme (EM)-like reaction and later understood to cause a blistering reaction similar to Stevens-Johnson syndrome/toxic epidermal necrolysis (SJS/TEN). $(4,5)$ Over the years, language used to describe disease caused by M. pneumoniae beyond the respiratory tract has included "incomplete" or "atypical" SJS or "Fuch's Syndrome".(5-7) It was not until recently that the cutaneous and clinical manifestations of this infection were understood as distinct and separate from both EM and SJS/TEN, hence the recent introduction of the term "Mycoplasma induced rash and mucositis" (MIRM).

MIRM is characterized as a predominantly mucosal eruption with relatively less prominent skin involvement. If skin is involved, the presentation is typically sparse in nature with mild vesiculobullous and/or targetoid lesions. $(8,9)$ MIRM has been found to affect males more than females, is most prevalent in children and young adults, and is often preceded by a prodromal viral syndrome.(9) MIRM is usually diagnosed based on clinical evidence of upper respiratory symptoms with evidence of mucositis in two or more mucosal sites. Initially, its diagnosis was solely based on clinical findings, but the standard of care now includes the measure of Mycoplasma IgM and IgG antibodies for confirmation and exclusion of other diagnoses. $(10,11)$ While there is no unanimously standard treatment for these patients, they are often treated with antibiotics, systemic corticosteroids, intravenous immunoglobulins or other immunomodulators; in some cases patients receive only supportive care. Fortunately, prognosis and recovery in patients affected by MIRM is excellent.

The current literature on ocular complications of MIRM is sparse. The ocular surface is reported to be involved anywhere between $82 \%-100 \%$ in MIRM cases. $(9,12-14)$ The most commonly reported ocular findings include conjunctivitis, blepharitis, subconjunctival hemorrhage, ulceration, and optic disc swelling; ocular signs are typically bilateral. Overall, conjunctivitis is documented as the most common ocular manifestation. $(9,12-14)$

Since patients with MIRM initially present with mucositis, SJS/TEN must be considered on the initial differential diagnosis and patients managed accordingly. However, unlike the skin lesions found in SJS/TEN, the lesions in MIRM do not typically progress to confluence, involve a large total body surface area, or show evidence of subsequent necrolysis. $(9,12)$ However, on initial presentation, there are strong clinical similarities to SJS/TEN, and it is unclear whether MIRM patients suffer the severe ocular 
complications characteristic of SJS/TEN. The purpose of this study is to describe the clinical course and specific ocular complications in patients diagnosed with MIRM.

\section{Methods}

This is a retrospective, descriptive study of patients at a hospital network conglomerate. The study was approved by the Institutional Review Board at Massachusetts Eye and Ear, in compliance with the Health Insurance Portability and Accountability Act (HIPAA), and adhered to the tenets of the Declaration of Helsinki. Informed consent was not required and waived by the Institutional Review Board at Massachusetts Eye and Ear for this retrospective study. Informed consent was obtained from patients whose images are shown in Figs. 1 and 2.

We identified all patients within our hospital network between 2008 and 2018 who were diagnosed with mucositis. We then subsequently screened these patients for a diagnosis with MIRM or MIRM-suspect. Diagnosis was confirmed by diagnostic criteria recommended by Canavan et al.(9) Criteria included: two or more affected mucosal sites, and evidence of atypical pneumonia. The number of mucosal sites involved and clinical/radiological evidence for atypical pneumonia were obtained from clinic records. Positive serology was defined by the presence of IgM against Mycoplasma pneumoniae, or a 4-fold or greater increase in specific IgG titers after two weeks. Positive laboratory values used were as defined by the laboratory (Massachusetts General Hospital Lab, Boston, MA and Mayo Department Lab Med/Path, Rochester, MN): equivocal antibody values for IgG and IgM were defined as 0.91 to 1.09 , and positive as $\geq 1.10$. We included patients with equivocal laboratory values in the setting of definitive clinical or radiological evidence of pneumonia, or patients with positive laboratory values, with or without clinical or radiological evidence of pneumonia. We excluded any patients who did not meet the diagnostic criteria above, as well as patients with absent clinical records in the acute phase, or patients with no ophthalmology records as this was our primary outcome of interest.

Data collected included patient age, gender, race, age at time of diagnosis, presence of an upper respiratory illness, presence and description of skin lesions, number of mucosal sites involved, laboratory data, as well as treatment regimen used. We also recorded ophthalmic data, as documented by an ophthalmologist in the acute phase. Data collected included the presence of conjunctival hyperemia, conjunctivitis, pseudomembranes, conjunctival epithelial defects, epithelial defects of the eyelid margin, lacrimal punctal scarring, corneal epithelial defects, and meibomitis. We also recorded details of any ophthalmic treatments. Any ocular findings were similarly documented for patients with ophthalmic records available after resolution of acute disease, defined for our purposes as $>3$ months from disease onset. The primary outcome measure was ocular complications in the acute phase of MIRM. Secondary outcomes included ocular complications more than three months after disease onset, and the bestcorrected visual acuity at the last follow-up visit.

\section{Statistical analysis.}

Data was entered using Microsoft Excel 2013 and analyzed using statistical package for social sciences (SPSS Inc., Chicago, IL, USA, version 24). Quantitative data were expressed as median and range, or mean \pm standard deviation (SD), depending on normality of the data.

\section{Results}

Demographic Characteristics

Of the 156 patients screened for evidence of mucositis, 15 were diagnosed with MIRM. Three patients did not meet all the aforementioned diagnostic criteria and one did not receive documented ophthalmic care in the acute phase. A total of 11 patients satisfied all inclusion and exclusion criteria and were included in our study. Detailed demographic information can be found in Table 1. The average age of our included patients was $22.2 \pm 15.2$ years, and the majority were males (63.6\%). 
Demographic characteristics of the whole cohort

\begin{tabular}{|c|c|}
\hline Parameter & Number of patients (\%) \\
\hline Age, years: $\leq 18,>18$ & $6(54.5 \%), 5(45.5 \%)$ \\
\hline Sex: Male, Female & $7(63.6 \%), 4(36.7 \%)$ \\
\hline \multirow[t]{2}{*}{ Race } & White: 9 patients \\
\hline & Non-white: 2 patients \\
\hline Recurrent reaction: $\mathrm{Y} / \mathrm{N}$ & $4(36.7 \%), 7(63.6 \%)$ \\
\hline If yes, number of recurrences (including current): $2-4,>4$ & $3(75 \%), 1(25 \%)$ \\
\hline Preceded by drug intake: $\mathrm{Y} / \mathrm{N}$ & $9(81.8 \%), 2(18.2 \%)$ \\
\hline Preceded by prodromal symptoms: $\mathrm{Y} / \mathrm{N}$ & $11(100 \%), 0(0 \%)$ \\
\hline Clinical or radiological evidence of $P N A^{*}: \mathrm{Y} / \mathrm{N}$ & $11(100 \%), 0(0 \%)$ \\
\hline Number of mucosal sites involved: $2,>2$ & $3(27.3 \%), 8(72.8 \%)$ \\
\hline Skin lesions present: $\mathrm{Y} / \mathrm{N}$ & $9(81.8 \%), 2(18.2 \%)$ \\
\hline $\begin{array}{l}\text { If yes, lesion description: sparse vesiculobullous lesions/scattered atypical targets, } \\
\text { targetoid }\end{array}$ & $8(88.9 \%), 1(11.1 \%)$ \\
\hline Cutaneous distribution: acral, truncal, generalized & $2(22.2 \%), 5(55.6 \%), 2(22.2 \%)$ \\
\hline Skin Biopsy performed: $\mathrm{Y} / \mathrm{N}$ & $3(27.3 \%), 8(72.8 \%)$ \\
\hline If yes, biopsy consistent with MIRM: $\mathrm{Y} / \mathrm{N}$ & $3(100 \%), 0(0 \%)$ \\
\hline Leukocytosis $\left(>11,000\right.$ white cells $\left./ \mathrm{mm}^{3}\right): \mathrm{Y} / \mathrm{N}$ & $6(54.5 \%), 5(45.4 \%)$ \\
\hline HSV* tested: $\mathrm{Y} / \mathrm{N}$ & $6(54.5 \%), 5(45.4 \%)$ \\
\hline If yes, positive titers: $\mathrm{Y} / \mathrm{N}$ & $2(33.3 \%), 4(66.7 \%)$ \\
\hline Systemic treatment regimen: & $4(36.4 \%)$ \\
\hline Antibiotics only & $1(9.1 \%)$ \\
\hline Steroids only & $1(9.1 \%)$ \\
\hline Immunomodulator only & $3(27.3 \%)$ \\
\hline Antibiotics + steroids & $1(9.1 \%)$ \\
\hline \multicolumn{2}{|l|}{ Antibiotics + steroids + immunomodulator } \\
\hline Total hospital duration: $<7$ days, $8-14$ days & 9 (81.8\%), 2 (18.2\%) \\
\hline
\end{tabular}

Three $(27.3 \%)$ of the patients were diagnosed with MIRM in a winter month (December-February), and 8 (72.7\%) were diagnosed in a non-Winter month. Four (36.7\%) of the patients reported a prior similar episode, while seven (63.6\%) patients presented with first-time episodes of MIRM. Of the four patients with putative recurrences, the number of recurrences ranged from two to six episodes. Of the 11 patients, $9(81.8 \%)$ had a history of drug intake within one week of the start of symptoms. Drugs taken included non-steroidal anti-inflammatory drugs (NSAIDs), antibiotics, and anti-viral medications, all of which were administered to treat prodromal symptoms.

Systemic manifestations 
All 11 patients presented with upper respiratory tract symptoms (cough and rhinorrhea and/or sore throat) as well as a documented fever above $100.4^{\circ} \mathrm{F}$ within one week of presentation. All $11(100 \%)$ showed radiological evidence of pneumonia on chest X-ray or had a clinical examination consistent with pneumonia. All patients had oral mucosal involvement. Skin lesions were sparse on initial examination in nine cases (81.8\%), and absent in two patients (18.2\%). Of the nine patients with skin lesions, eight (88.9\%) presented with a few vesiculobullous lesions/scattered atypical targets, and one (11.1\%) with classic targetoid lesions. Cutaneous distribution was found to be acral in two patients, truncal in five patients, and generalized in two patients. Skin biopsy was performed in only three of the patients with skin involvement. All biopsies revealed trans-epithelial necrosis with focal subjacent mixed inflammatory infiltration. See Fig. 1A-C for examples of clinical findings.

Six (54.5\%) of the patients had leukocytosis (defined as $>11$ white cells $/ \mathrm{mm}^{3}$ ) on acute presentation. Herpes simplex titers were ordered in six patients and confirmed positive for HSV IgG in two of the patients; none were positive for HSV IgM. Blood cultures were drawn in six patients; none were positive.

Patients underwent therapy with a variety of medications including systemic steroids, immunomodulators, and antibiotics (azithromycin and/or levofloxacin). The average total duration of admission was $6 \pm 2.9$ days. Hospital duration was less than one week in nine patients (81.8\%), and between 8 and 14 days in the remaining 2 (18.2\%) patients. One of these patients remained admitted for 14 days with severe oral mucositis requiring total parental nutrition due to poor oral intake. The other patient was admitted for 8 days for non-medical reasons. There were no reported mortalities and all eleven patients fully recovered with no complications.

Ocular manifestations

All 11 patients included in the study were examined by an ophthalmologist within two days of admission. Ocular complications were recorded as shown in Table 2. Out of the 22 total eyes, the most common complication was the presence of conjunctival hyperemia ( $n=18,81.8 \%)$, followed by meibomitis $(n=2,9.1 \%)$, and conjunctival epithelial defects $(n=1,4.5 \%)$. The one eye with evidence of conjunctival defect on initial exam showed improvement with medical therapy within the course of the hospital admission and was previously reported as a "clinical challenge" case study.(15) Table 3 summarizes the clinical characteristics in pediatric ( $\leq 18$ years) and adult patients ( $>18$ years). None of the patients received or were recommended by the ophthalmologist to receive amniotic membrane transplantation or a ProKera ${ }^{\circledR}$ device. The majority of eyes $(n=18,81.8 \%)$ received triple therapy in the acute phase with topical antibiotics, lubricants, and corticosteroids. Of the remaining eyes, two received treatment with topical antibiotic and lubricant alone, and two eyes received topical lubricant alone. Please see Fig. 1D for example of acute ocular involvement in our cohort. 
Table 2

Acute ocular complications and treatment of all 11 included patients

(22 eyes)

\begin{tabular}{|ll|}
\hline Ocular complication or treatment & Number of eyes (\%) \\
\hline Conjunctival hyperemia & $18(81.8 \%)$ \\
\hline Conjunctival epithelial defect & $1(4.5 \%)$ \\
\hline Meibomitis & $2(9.1 \%)$ \\
\hline Defects of the epithelium at the eyelid margin & $0(0 \%)$ \\
\hline Pseudomembranous conjunctivitis & $0(0 \%)$ \\
\hline Corneal epithelial defect & $0(0 \%)$ \\
\hline Symblepharon & $0(0 \%)$ \\
\hline AMT/ProKera device used or recommended & $0(0 \%)$ \\
\hline Ocular treatment regimen & $18(81.8 \%)$ \\
Steroid, antibiotic, lubricant & $2(9.1 \%)$ \\
Antibiotic and lubricant & $2(9.1 \%)$ \\
\hline Lubricant only & \\
\hline AMT: amniotic membrane transplantation & \\
\hline
\end{tabular}

Table 3

Clinical characteristics of mycoplasma pneumoniae induced mucositis and rash (MIRM) in patients $\leq 18$ years old compared to those $>18$ years old at the time of presentation.

\begin{tabular}{|lll|}
\hline & Patients $\leq 18$ years & Patients $>18$ years \\
\hline Number of patients & 6 & 5 \\
\hline Mean age at the time of presentation $( \pm$ SD) & $10.8 \pm 2.1$ years & $36 \pm 11.1$ years \\
\hline Preceded by drug intake & $4 / 6$ patients & $5 / 5$ patients \\
\hline Number of mucosal sites involved & 2 sites: 1 patient & 2 sites: 2 patients \\
\hline Recurrent reaction & $>2$ sites: 5 patients & $>2$ sites: 3 patients \\
\hline Conjunctival hyperemia & $3 / 6$ patients & $1 / 5$ patients \\
\hline Meibomitis & $5 / 6$ patients & $4 / 5$ patients \\
\hline Conjunctival epithelial defects & $1 / 6$ patients & $0 / 5$ patients \\
\hline SD: standard deviation & $0 / 6$ patients & $1 / 5$ patients \\
\hline
\end{tabular}

Of the 11 patients, only three had a later ophthalmic examination in our center, defined as occurring more than 3 months from disease onset. Findings included mild distichiatic and/or trichiatic eyelashes in two patients and no complications in the third. No meibomitis, corneal disease, or eyelid margin keratinization were recorded on any patient on follow-up. All patients had a recorded best-corrected visual acuity of $20 / 20$ in both eyes at the time of their last follow-up. Please see Fig. 2 for examples of chronic ocular disease in our cohort.

\section{Discussion}


Our results in 22 eyes show that ocular complications of MIRM are restricted to conjunctival hyperemia (81.8\%), meibomitis $(9.1 \%)$ and conjunctival epithelial defects $(4.5 \%)$ in the acute phase. We believe late complications are unusual. It is important to understand ocular complications in MIRM, as in the acute phase, overlap with those of SJS/TEN. The differential diagnosis for patients with suspected MIRM includes SJS/TEN, as both conditions present with prodromal symptoms and mucositis. Additionally, patients with MIRM are often treated with nonsteroidal anti-inflammatory agents and antibiotics in the acute phase to treat prodromal symptoms, which can precede a mucositis quite similar in appearance to that of SJS/TEN. MIRM tends to recur in younger patients, as evident in our patient population. The male predominance in the current study is comparable to previously published studies. $(13,14)$ Neither is particularly helpful in distinguishing the two entities. One way to differentiate the two is with clinical and/or radiological signs of atypical pneumonia as well as, more definitively, with serology.

In several studies describing ocular manifestations of SJS/TEN in the acute phase, patients with Mycoplasma pneumoniae infections with skin manifestations have been typically grouped with SJS/TEN patients.(16-18) Therefore, it is difficult to decipher the severity of the ocular complications in the acute phase in patients with MIRM compared to those in SJS/TEN patients associated with infection with Mycoplasma. The prevalence of ocular complications in SJS/TEN has been found to be anywhere between $50 \%$ and $88 \%$. $(17,18)$ Complications in the acute phase include conjunctival hyperemia, pseudomembranous conjunctivitis, conjunctival and corneal epithelial defects. $(17,18)$ If not managed adequately in the acute phase, these complications can become long-standing problems, leading to persistent ocular inflammation and total limbal stem cell deficiency (LSCD). $(19,20)$

In comparison, ocular findings in patients with MIRM have been documented in up to $82 \%$ of cases. $(9,12-14)$ However, this may be an overestimate as there are few reports of MIRM in the literature to date, and a likely bias for reporting the more severe cases. Nonetheless, reports on ocular complications in these patients primarily describe milder symptoms, particularly in younger patients.(9) The largest systematic review of MIRM cases was conducted by Canavan et al. who evaluated 202 MIRM patients.(9) They reported that $82 \%$ of their patients had ocular manifestations, the most common of which were bilateral conjunctivitis, sometimes associated with photophobia. Another systematic literature review by Vujic et al. demonstrated ocular complications in $100 \%$ of their identified 12 patients, with mention of severe bilateral conjunctivitis in one patient but no discussion of specific complications in any of the other cases.(21) Similarly, Langley et al. described Mycoplasma pneumoniae positivity in 22 of their 65 patients and reported an ocular complication rate of $82 \%$ in all their cases, including non-MIRM patients. The reported complications included conjunctivitis and keratitis, however, most of their cohort were non-MIRM patients.(16) Additionally, in all these reports, there was no mention of late ocular manifestations in any of the patients. We believe that the absence of reports on chronic complications of MIRM can be attributed to the fact that the acute disease is typically mild and that bilateral conjunctivitis, the most common acute complication, is typically transient and/or well-controlled with topical corticosteroids. This was evident in our six eyes of three patients with chronic follow-up. A recent study by Gise et al. including 15 MIRM patients with a mean follow-up of 13.6 months reported thirteen patients who had ocular manifestations. Three patients received amniotic membrane transplantation and one patient underwent ProKera ${ }^{\circledR}$ placement. The rest were controlled with systemic and topical therapy. They reported one patient who developed mild bilateral symblephara and another patient with eyelid margin scarring.(14) Their series did not include adults. In our series, which included 10 adult eyes, no patients underwent AMT or ProKera placement though this alone cannot be used as a marker of severe disease as the threshold for placement may be different between our institutions. However, none of our patients with follow-up after discharge had symblephara or eyelid margin disease.

There have been other, mostly single-patient, case reports in the literature of patients with MIRM with severe ocular findings in the acute phase (Table 4). These reports demonstrate acute ocular complications including bilateral conjunctivitis, pseudomembranous conjunctivitis, symblepharon, and extensive corneal epithelial defects.(22-26) The reports all confirmed MIRM based on serology and all patients received systemic treatment. It is unclear why these patients developed more severe acute ocular complications than most other MIRM cases described in the literature. Nonetheless, while these reports show evidence of severe acute complications, the majority of the literature to date on MIRM report much milder ocular complications. 
Table 4

Reports to date of acute ocular complications in patients diagnosed with Mycoplasma Induced Rash and Mucositis (MIRM)

\begin{tabular}{|c|c|c|c|c|c|c|}
\hline Report & $\begin{array}{l}\text { Number of } \\
\text { Patients//eyes }\end{array}$ & $\begin{array}{l}\text { Diagnosis } \\
\text { confirmed } \\
\text { by clinical } \\
\text { evidence } \\
\text { and/or } \\
\text { serology? }\end{array}$ & Systemic treatment & $\begin{array}{l}\text { Acute ocular } \\
\text { complications }\end{array}$ & Ocular Treatment & $\begin{array}{l}\text { Resolution } \\
\text { of } \\
\text { systemic } \\
\text { and ocular } \\
\text { disease } \\
\text { with } \\
\text { treatment? }\end{array}$ \\
\hline $\begin{array}{l}\text { John et } \\
\text { al. }^{21}\end{array}$ & $1 / / 2$ & Yes & Antibiotics & $\begin{array}{l}\text { Swelling of eyelids } \\
\text { with adhesion to the } \\
\text { ocular surface, } \\
\text { bilateral corneal } \\
\text { defects, diffuse } \\
\text { keratoconjunctivitis, } \\
\text { conjunctival edema }\end{array}$ & $\begin{array}{l}\text { Topical antibiotic } \\
\text { and AMT }\end{array}$ & Yes \\
\hline $\begin{array}{l}\text { Varghese } \\
\text { et al. }{ }^{22}\end{array}$ & $1 / / 2$ & Yes & Antibiotics & $\begin{array}{l}\text { Bilateral } \\
\text { conjunctival } \\
\text { injection, significant } \\
\text { corneal abrasions } \\
\text { and symblepharon }\end{array}$ & $\begin{array}{l}\text { Topical antibiotic } \\
\text { and AMT }\end{array}$ & Yes \\
\hline $\begin{array}{l}\text { Dhaliwal } \\
\text { and } \\
\text { Enright }{ }^{23}\end{array}$ & $1 / / 2$ & Yes & Steroids & $\begin{array}{l}\text { Bilateral } \\
\text { subconjunctival } \\
\text { hemorrhage, } \\
\text { pseudomembranous } \\
\text { conjunctivitis }\end{array}$ & $\begin{array}{l}\text { Topical antibiotic, } \\
\text { steroids, and AMT }\end{array}$ & Yes \\
\hline $\begin{array}{l}\text { Santos } \\
\text { et al. }{ }^{24}\end{array}$ & $2 / / 4$ & Yes & Steroids and IVIG & $\begin{array}{l}\text { Bilateral } \\
\text { conjunctival } \\
\text { injection ( } 2 \text { patients) } \\
\text { and right corneal } \\
\text { ulcer ( } 1 \text { patient) }\end{array}$ & $\begin{array}{l}\text { Occlusion therapy } \\
\text { and topical } \\
\text { antibiotics }\end{array}$ & Yes \\
\hline $\begin{array}{l}\text { Jin et } \\
\text { al. }^{25}\end{array}$ & $1 / / 2$ & Yes & Antibiotics & $\begin{array}{l}\text { Bilateral } \\
\text { subconjunctival } \\
\text { hemorrhages, } \\
\text { corneal epithelial } \\
\text { defects and } \\
\text { pseudomembrane } \\
\text { formation }\end{array}$ & $\begin{array}{l}\text { Topical steroids, } \\
\text { antibiotics and } \\
\text { ProKera placement }\end{array}$ & Yes \\
\hline $\begin{array}{l}\text { Shah et } \\
\text { al. }{ }^{13}\end{array}$ & $5 / / 10$ & Yes & $\begin{array}{l}\text { Antibiotics with or } \\
\text { without steroids } \\
\text { and supportive care }\end{array}$ & $\begin{array}{l}\text { Diffuse conjunctival } \\
\text { injection, } \\
\text { conjunctival } \\
\text { pseudomembranes, } \\
\text { conjunctival } \\
\text { epithelial defects, } \\
\text { eyelid margin } \\
\text { hyperemia, ulcerated } \\
\text { eyelid margin }\end{array}$ & $\begin{array}{l}\text { Topical steroids } \\
\text { with or without } \\
\text { topical antibiotics }\end{array}$ & Yes \\
\hline $\begin{array}{l}\text { Gise et } \\
\text { al. }{ }^{14}\end{array}$ & $15 / / 30$ & Yes & $\begin{array}{l}\text { Antibiotics, } \\
\text { steroids, IVIG }\end{array}$ & $\begin{array}{l}\text { Conjunctival } \\
\text { injection, eyelid } \\
\text { margin staining, } \\
\text { superficial punctate } \\
\text { keratitis }\end{array}$ & $\begin{array}{l}\text { Topical } \\
\text { steroids/antibiotics, } \\
\text { topical } \\
\text { cyclosporine, AMT, } \\
\text { and/or ProKera }\end{array}$ & Yes \\
\hline $\begin{array}{l}\text { Current } \\
\text { study }\end{array}$ & $11 / / 22$ & Yes & $\begin{array}{l}\text { Antibiotics, } \\
\text { steroids, } \\
\text { immunomodulators }\end{array}$ & $\begin{array}{l}\text { Conjunctival } \\
\text { injection, meibomitis } \\
\text { conjunctival } \\
\text { epithelial defects }\end{array}$ & $\begin{array}{l}\text { Topical steroids, } \\
\text { antibiotics, and } \\
\text { lubricants }\end{array}$ & Yes \\
\hline
\end{tabular}

Shah et al. evaluated five MIRM patients with a mean age of 11.9 years. Ocular manifestations in the five patients were mild and none of them received amniotic membrane transplantation.(13) The mean age of patients in our study is older than what was 
reported by Shah et al. and Gise et al. and includes adults.(13,14) Though our sample size is not large enough to detect differences in presentation or outcomes between adult and children, our data appear to be similar between the two.

Systemic disease management remains widely variable given the rarity of the condition. However, the treatment modalities used in our patients and other MIRM patients described in the literature are very similar to that used in the management of SJS/TEN patients. $(27,28)$ Patients with MIRM also typically receive a course of antibiotics, most commonly azithromycin. $(9,29)$

There are limitations of the current study which hinder the broad applicability of our results. Given the retrospective nature of the study and small sample size, no definitive conclusions can be drawn. The lack of late follow-up examinations for most of the cases in our study are also a limitation. However, the fact that most of these patients did not return for follow-up speaks to the relatively mild character of ocular findings as our follow up rates for more severe disease such as SJS/TEN in the same timeframe is much higher (30). Our patients with MIRM who did have follow up examinations all had very mild or no chronic ocular disease and experienced 20/20 BCVA. Nonetheless, the similarities between MIRM and SJS/TEN at onset of signs and symptoms warrants an ophthalmology consult in every case of suspected MIRM.

In conclusion, our cohort of patients further supports the notion that MIRM is an entity separate from other mucocutaneous conditions, with its own prognosis and set of potential complications. Larger, multicenter studies are needed to truly assess the difference in ocular severity between patients with MIRM and SJS/TEN and to characterize acute and chronic disease.

\section{Declarations}

\section{Ethics approval and consent to participate}

The study was approved by Institutional Review Board at Massachusetts Eye and Ear. The study was conducted under Health Insurance Portability and Accountability Act (HIPAA) compliance and adhered to the tenets of the Declaration of Helsinki.

\section{Acknowledgments}

The project described was supported by the National Eye Institute, National Institutes of Health, Award Number K23EY028230. The content is solely the responsibility of the authors and does not necessarily represent the official views of the $\mathrm{NIH}$.

\section{Author Contributions}

Conception and design of the manuscript was done by JC and HNS. Data collection was done by RR, AE, and SSS. Analysis and interpretation were done by RR, AE, SSS, JC, and HNS. All authors reviewed the manuscript.

\section{Competing interests}

The authors declare that there is no conflict of interest regarding the publication of this paper.

\section{References}

1. Saraya T. The History of Mycoplasma pneumoniae Pneumonia. Frontiers in Microbiology. 2016;7(364).

2. Narita M. Pathogenesis of extrapulmonary manifestations of $<$ em $>$ Mycoplasma pneumoniae $</$ em $>$ infection with special reference to pneumonia. Journal of Infection and Chemotherapy. 2010;16(3):162-9.

3. Dhaliwal K, Enright K. Rare extrapulmonary complications of <em $>$ Mycoplasma pneumoniae</em> infection. BMJ Case Reports. 2016;2016:bcr2015214044.

4. Tay Y-K, Huff JC, Weston WL. <em>Mycoplasma pneumoniae</em> infection is associated with Stevens-Johnson syndrome, not erythema multiforme (von Hebra). Journal of the American Academy of Dermatology. 1996;35(5):757-60. 
5. Hillebrand-Haverkort ME, Budding AE, bij de Vaate LA, van Agtmael MA. Mycoplasma pneumoniae infection with incomplete Stevens-Johnson syndrome. Lancet Infect Dis. 2008;8(10):586-7.

6. Yachoui R, Kolasinski SL, Feinstein DE. Mycoplasma Pneumoniae with Atypical Stevens-Johnson Syndrome: A Diagnostic Challenge. Case Reports in Infectious Diseases. 2013;2013:457161.

7. Li K, Haber RM. Stevens-Johnson Syndrome Without Skin Lesions (Fuchs Syndrome): A Literature Review of Adult Cases With Mycoplasma Cause. Archives of Dermatology. 2012;148(8):963-4.

8. Amode R, Ingen-Housz-Oro S, Ortonne N, Bounfour T, Pereyre S, Schlemmer F, et al. Clinical and histologic features of Mycoplasma pneumoniae-related erythema multiforme: A single-center series of 33 cases compared with 100 cases induced by other causes. J Am Acad Dermatol. 2018;79(1):110-7.

9. Canavan TN, Mathes EF, Frieden I, Shinkai K. Mycoplasma pneumoniae-induced rash and mucositis as a syndrome distinct from Stevens-Johnson syndrome and erythema multiforme: a systematic review. J Am Acad Dermatol. 2015;72(2):239-45.

10. Thurman KA, Walter ND, Schwartz SB, Mitchell SL, Dillon MT, Baughman AL, et al. Comparison of laboratory diagnostic procedures for detection of Mycoplasma pneumoniae in community outbreaks. Clin Infect Dis. 2009;48(9):1244-9.

11. Norton SA. Diagnosing Mycoplasma pneumoniae-induced rash and mucositis (MIRM) in the emergency room. J Am Acad Dermatol. 2015;73(2):e67.

12. Meyer Sauteur PM, Goetschel P, Lautenschlager S. Mycoplasma pneumoniae and mucositis-part of the Stevens-Johnson syndrome spectrum. J Dtsch Dermatol Ges. 2012;10(10):740-6.

13. Shah PR, Williams AM, Pihlblad MS, Nischal KK. Ophthalmic Manifestations of Mycoplasma-Induced Rash and Mucositis. Cornea. 2019;38(10):1305-8.

14. Gise R, Elhusseiny AM, Scelfo C, Mantagos IS. Mycoplasma Pneumoniae-Induced Rash and Mucositis: A Longitudinal Perspective and Proposed Management Criteria. Am J Ophthalmol. 2020;219:351-6.

15. Benchetrit L, van Zyl T, Chodosh J. Bilateral Limbus-Sparing Conjunctivitis in a Boy With Rash and Pneumonia. JAMA Ophthalmol. 2019;137(11):1323-1324.

16. Langley A, Anooshiravani N, Kwan S, Zeller J, Pope E. Erythema Multiforme in Children and Mycoplasma pneumoniae Aetiology. J Cutan Med Surg. 2016;20(5):453-7.

17. Saeed HN, Chodosh J. Ocular manifestations of Stevens-Johnson syndrome and their management. Curr Opin Ophthalmol. 2016;27(6):522-9.

18. Kohanim S, Palioura S, Saeed HN, Akpek EK, Amescua G, Basu S, et al. Stevens-Johnson Syndrome/Toxic Epidermal Necrolysis-A Comprehensive Review and Guide to Therapy. I. Systemic Disease. Ocul Surf. 2016;14(1):2-19.

19. López-García JS, Rivas Jara L, García-Lozano Cl, Conesa E, de Juan IE, Murube del Castillo J. Ocular features and histopathologic changes during follow-up of toxic epidermal necrolysis. Ophthalmology. 2011;118(2):265-71.

20. Oplatek A, Brown K, Sen S, Halerz M, Supple K, Gamelli RL. Long-term follow-up of patients treated for toxic epidermal necrolysis. J Burn Care Res. 2006;27(1):26-33.

21. Vujic I, Shroff A, Grzelka M, Posch C, Monshi B, Sanlorenzo M, et al. Mycoplasma pneumoniae-associated mucositis-case report and systematic review of literature. J Eur Acad Dermatol Venereol. 2015;29(3):595-8.

22. John T, Foulks GN, John ME, Cheng K, Hu D. Amniotic membrane in the surgical management of acute toxic epidermal necrolysis. Ophthalmology. 2002;109(2):351-60. 
23. Varghese C, Sharain K, Skalski J, Ramar K. Mycoplasma pneumonia-associated mucositis. BMJ Case Rep. $2014 ; 2014$.

24. Dhaliwal K, Enright K. Rare extrapulmonary complications of Mycoplasma pneumoniae infection. BMJ Case Rep. 2016;2016.

25. Santos RP, Silva M, Vieira AP, Brito C. Mycoplasma pneumoniae-induced rash and mucositis: a recently described entity. BMJ Case Rep. 2017;2017.

26. Jin HD, Siatkowski RM, Siatkowski RL. Ocular manifestations of mycoplasma-induced rash and mucositis. Journal of American Association for Pediatric Ophthalmology and Strabismus \{JAAPOS\}. 2020;24(4):249-51.

27. Chang VS, Chodosh J, Papaliodis GN. Chronic Ocular Complications of Stevens-Johnson Syndrome and Toxic Epidermal Necrolysis: The Role of Systemic Immunomodulatory Therapy. Semin Ophthalmol. 2016;31(1-2):178-87.

28. Kim DH, Yoon KC, Seo KY, Lee HS, Yoon SC, Sotozono C, et al. The role of systemic immunomodulatory treatment and prognostic factors on chronic ocular complications in Stevens-Johnson syndrome. Ophthalmology. 2015;122(2):254-64.

29. Salzman MB, Sood SK, Slavin ML, Rubin LG. Ocular manifestations of Mycoplasma pneumoniae infection. Clin Infect Dis. 1992;14(5):1137-9.

30. Shanbhag SS, Hall L, Chodosh J, Saeed HN. Long-term outcomes of amniotic membrane treatment in acute Stevens-Johnson syndrome/toxic epidermal necrolysis. Ocul Surf. 2020 Jul;18(3):517-522.

\section{Figures}



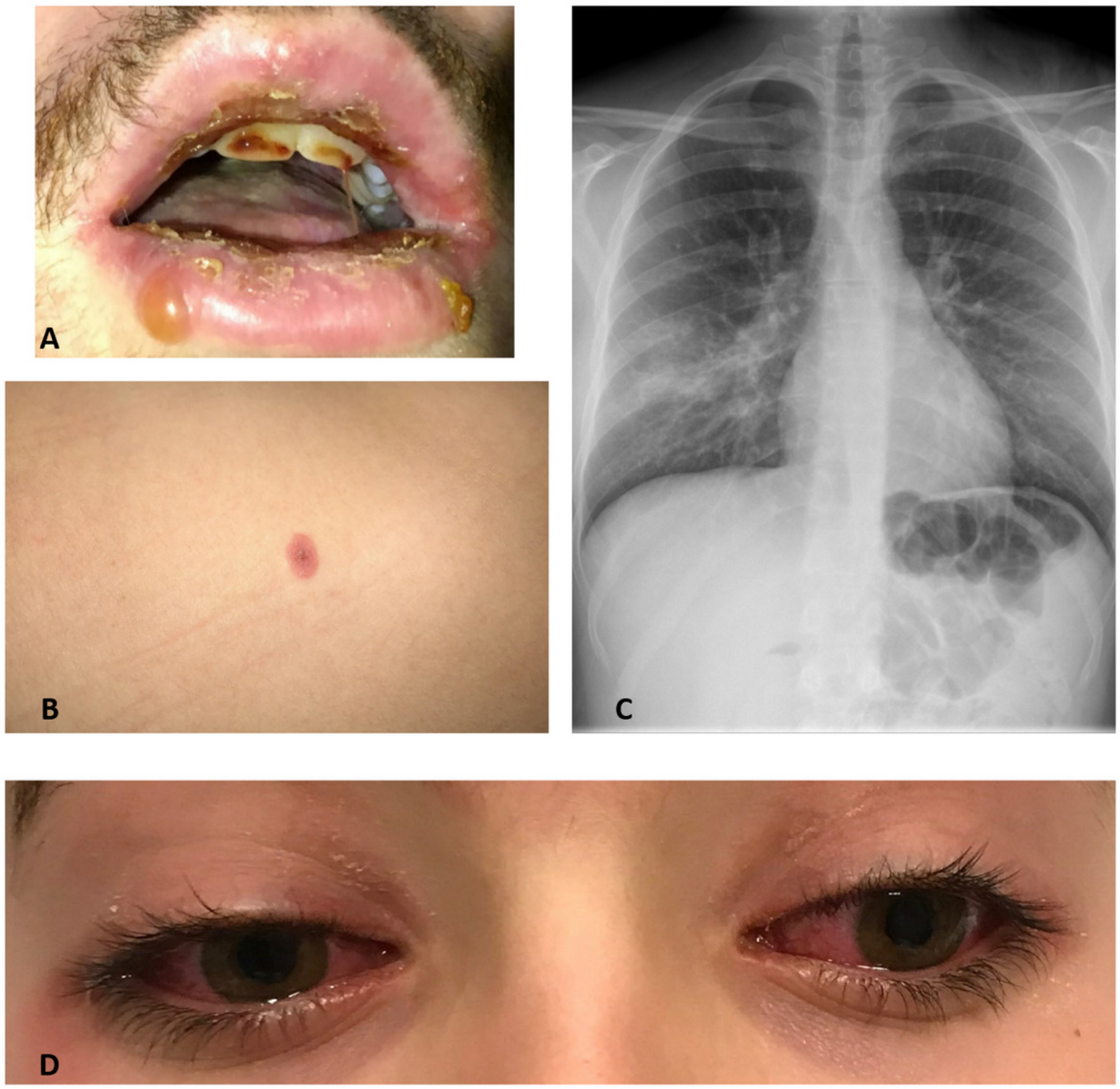

\section{Figure 1}

Acute systemic and ocular manifestations of Mycoplasma induced mucositis and rash including A) mucositis and lip blisters, B) target-like skin lesion, C) chest X-ray showing right middle lobe pneumonia, D) acute bilateral conjunctival hyperemia and erythematous periorbital skin. 

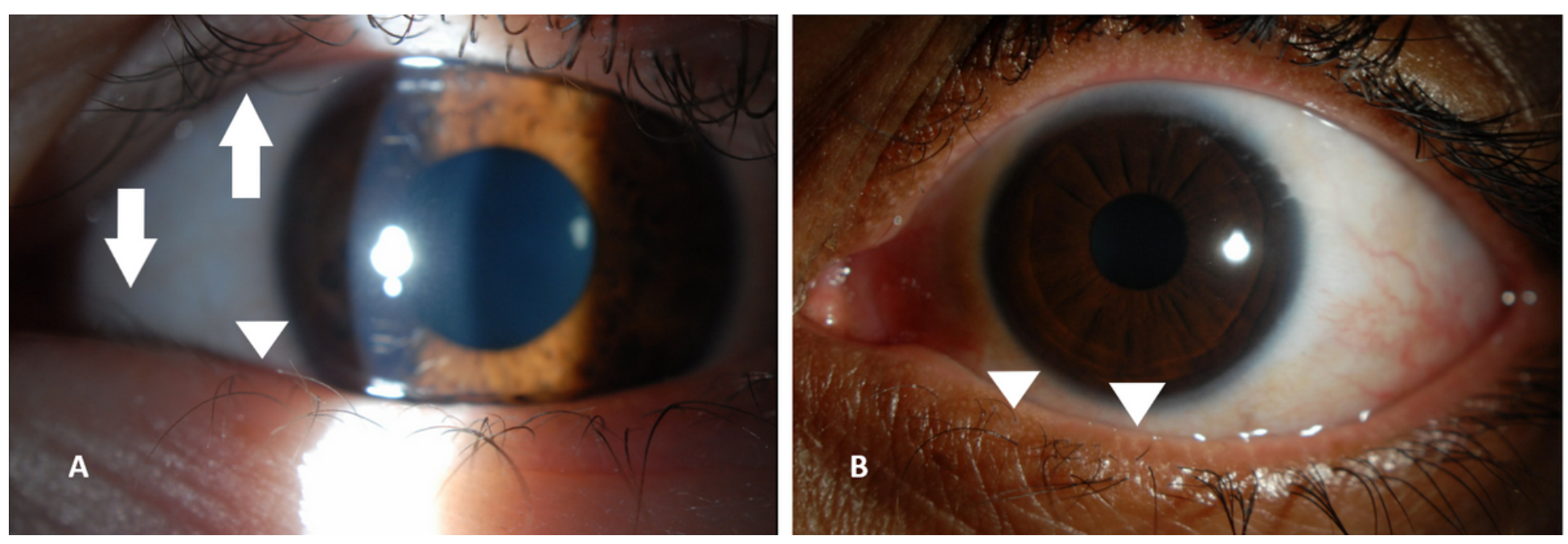

\section{Figure 2}

Chronic ocular involvement in the form of A) very mild trichiasis (arrow) and distichiasis (arrowhead) and B) very mild distichiasis of lower eyelid (arrowhead). 